\title{
Factors associated with patient selection for inpatient rehabilitation: an audit of decision- making in the rehabilitation assessment
}

This article was published in the following Dove Press journal:

Clinical Audit

18 January 2013

Number of times this article has been viewed

\section{Joanne Lim' \\ Leonid Churilov \\ Penelope Smith' \\ Irina Churilov'}

'Rehabilitation Unit, St Vincent's Health, Fitzroy, Victoria, Australia; ${ }^{2}$ Florey Institute of Neuroscience and Mental Health, Melbourne, Victoria, Australia
Correspondence: Irina Churilov Rehabilitation Unit, St Vincent's Health, Fitzroy, Victoria 3065, Australia

Tel +6I 409528523

Fax +6I 39288390 I

Email irina.churilov@gmail.com
Background: Assessment of patients for their potential to participate and benefit from inpatient rehabilitation forms an integral component of the practice of rehabilitation medicine. There is limited information in the current literature to guide or standardize the decision-making in rehabilitation assessment.

Setting: Inpatient rehabilitation unit within a major tertiary public hospital in metropolitan Melbourne, Australia.

Objective: To determine which information routinely collected during the rehabilitation assessment is associated with the likelihood of a patient being accepted for inpatient rehabilitation.

Design: A retrospective audit of consecutive rehabilitation assessments carried out over a 4-month period.

Methods: Multivariable association between patient clinical and demographic characteristics and the likelihood of being accepted for inpatient rehabilitation was assessed for 219 acute inpatients referred to the inpatient rehabilitation unit.

Results: Of the 219 patients, $74.9 \%$ were accepted for inpatient rehabilitation. There were statistically significant deficits in cognition, continence, personal care, and mobility at the time of patients' assessment for inpatient rehabilitation. Patients' premorbid level of independence with personal activities of daily living (PADLs) $(P=0.006)$ and continence $(P=0.04)$, as well as "at the time of assessment" need for assistance with PADLs $(P<0.001)$, mobility $(P=0.004)$, incontinence $(P=0.01)$, and impaired cognition $(P<0.001)$, were associated with the likelihood of being accepted for inpatient rehabilitation.

Conclusion: Premorbid dependence with PADLs and current impaired cognition as well as incontinence reduce the likelihood of patient selection, while present dependence with PADLs and mobility increase the likelihood of patient admission. Our findings provide researchers, clinicians, and health managers with empirical evidence regarding the process of patient selection for inpatient rehabilitation.

Keywords: rehabilitation, disability evaluation, rehabilitation centers, medical decisionmaking

\section{Introduction}

The assessment of patients for their potential to participate in and benefit from inpatient rehabilitation forms an integral component of the practice of rehabilitation medicine. Patients are often referred by acute medical or surgical units for consideration of inpatient rehabilitation. It is the responsibility of the rehabilitation physician or trainee to undertake a comprehensive assessment of the patient to determine the need for rehabilitation, and the ideal setting for this to occur. 
Haas $^{1}$ described the common factors related to health conditions, functioning, disability, and body function ${ }^{2}$ that affect this decision-making process. Medical factors include diagnosis; prognosis; secondary diseases; complications; medical stability; and the patient's present as well as anticipated levels of functional performance in communication, mobility, and self-care. Nonmedical factors that influence patient selection include social factors such as availability and reliability of discharge supports; financial issues, including insurance coverage and bed availability; ${ }^{3,4}$ and past experiences of the assessor or rehabilitation unit. ${ }^{5}$

A recent literature review by $\mathrm{New}^{6}$ specifically emphasizes the point that there is limited information in current literature to guide or standardize the decision-making in rehabilitation assessment. The general opinion is that the process of patient selection remains a subjective practice, ${ }^{7-9}$ which relies predominantly on clinical judgment and is influenced by system factors such as rehabilitation bed availability and pressure on acute care.

It is commonly accepted that rehabilitation is a "goal-oriented specialty" 10 with the objective "to restore optimal patient function" 11 and "to maximize functional independence" 10 in "patients with disability,"10 whose "common denominator is loss of function." ${ }^{10}$ This understanding implies that in order to participate in a rehabilitation process, a patient should have a disability ${ }^{2}$ in the form of functional impairment at the time of assessment. The other logical implication is that certain patient characteristics would be associated with the assessor's perception of the patient's ability to achieve relevant rehabilitation goals, and, therefore, these characteristics would be associated with the likelihood of a patient being accepted for inpatient rehabilitation.

The role of rehabilitation internationally is described as being very similar to that in Australia. For instance, physical medicine and rehabilitation (the equivalent specialty in USA) is described as looking after patients who are "temporarily injured to $[\ldots]$ severely impaired," aiming to put in place a

[...] rehabilitation plan that provides the best possible outcomes for these patients [...]. [Rehabilitation] [...] uses physical agents and therapeutic exercise in the prevention, diagnosis, treatment and rehabilitation of disorders that produce pain, impairment and disability. ${ }^{12}$

In the UK, the task of rehabilitation is "to promote the understanding and multidisciplinary management of acute and chronic disabling diseases and injuries; their personal interpersonal and social consequences."13 Inpatient rehabilitation is an important discharge destination both in Australia and internationally.
The aim of this audit is to determine empirically whether any of the routine information considered during the rehabilitation assessment, including the patient's current and premorbid functioning - specifically, cognitive function, mobility, participation in personal care, continence, residential status and diagnosis of health condition - are associated with the likelihood of a patient being accepted for inpatient rehabilitation. We therefore hypothesized that:

1. there is a difference in premorbid and "at the time of assessment" level of functioning in patients being assessed for inpatient rehabilitation, specifically in the areas of cognition, continence, personal care, and mobility status; and

2. the patient's premorbid and "at the time of assessment" functioning - specifically, cognitive function, mobility, participation in personal care, continence, residential status, and diagnosis - are associated with the likelihood of a patient being accepted for inpatient rehabilitation.

In this audit, we follow the World Health Organization International Classification of Functioning, Disability and Health framework and terminology ${ }^{2}$ to describe patients' health condition, functioning, and disability.

\section{Methods}

\section{Study settings}

This audit involved a retrospective analysis of consecutive rehabilitation assessments of acute inpatients referred to the inpatient rehabilitation unit located within the campus of a major tertiary public hospital that provides a wide range of medical and surgical services, including neurosurgery and cardiac surgery, and has 334 acute care beds. The funding of the hospital is based on patients' length of admission and diagnosis of health condition. Patients who have completed their acute admission can be discharged to home, inpatient rehabilitation unit, geriatric evaluation and management (GEM) unit, palliative care, or residential care.

The inpatient rehabilitation unit consists of a 26-bed ward and provides a general rehabilitation service, covering neurological, musculoskeletal, restorative, spinal, amputee, and cardiac rehabilitation. Approximately 400 patients are admitted to the unit each year, with an average length of stay of 22 days. When compared to the relevant benchmark group as per the Australasian Rehabilitation Outcomes Centre, ${ }^{14}$ the case-mix of this inpatient rehabilitation unit could be characterized as having greater-than-average proportion of younger patients, patients with neurological impairment other than stroke (including patients recovering from brain surgery), and cardiac impairment, and a less-than-average 
proportion of patients with stroke, fractures, and reconditioning impairment. The general admission criteria to the unit are similar to that of other rehabilitation facilities: the patient has a functional disability, would benefit from interdisciplinary treatment, would be able to participate in daily therapy, and would be able to learn new information. ${ }^{15}$

Patients who are deemed by their acute treating unit to likely require inpatient rehabilitation are referred to the rehabilitation unit for assessment. The decision to refer to rehabilitation or another discharge destination is generally made when the acute units decide that the patient no longer needs to be under their care, but cannot be safely discharged to their premorbid residence. The patient is generally referred to rehabilitation if they are deemed likely to improve with intensive allied health input; to GEM if they are expected to make slower gains in function and are older than 65 years; to palliative care if they are not expected to improve and have a prognosis of several months; and to residential care if they are not expected to improve but have a prognosis of greater than several months. The acute units are often guided in whom they refer to by allied health staff on the acute ward. If the unit that receives the referral feels that the patient would be more appropriate to another discharge destination, the referral can be redirected.

The uncomplicated musculoskeletal referrals to rehabilitation are assessed by a nurse, who does not use a standardized form. These patients are largely admitted for elective joint replacements and management of uncomplicated fractures, and about 12 patients per month are referred for assessment for inpatient rehabilitation. All other referrals (about 50 per month) are assessed by either the rehabilitation consultants or a rehabilitation registrar. Patients who are accepted for inpatient rehabilitation are sometimes referred to rehabilitation units closer to their expected discharge destination. The patients who are not accepted for inpatient rehabilitation can be discharged to home, GEM, palliative care, or residential care.

\section{Standardized assessment forms}

The standardized form is used by the medical staff for each patient other than patients with uncomplicated musculoskeletal problems, to document diagnosis of health condition, complications, current and premorbid function (including cognition, mobility, activities of daily living, and continence), social history, and outcome of assessment (ie, whether the patient has been accepted for inpatient rehabilitation). Premorbid function refers to the patients' function in the period of time immediately preceding the illness for which they are admitted, ie, preoperative function for elective surgery and function before the onset of illness for other patients. "Current function" refers to the level of function at the time of the rehabilitation assessment.

Information in the forms is usually obtained through a combination of general clinical assessment, review of current admission notes and verbal discussions with the nursing staff and acute treating therapists, such as physiotherapists, who see every referred patient, and in some cases, occupational therapist, speech pathologist, and social worker. The structured assessment form reflects the following information:

- clinical diagnosis and details of medical and surgical management;

- mobility measured on a binary scale as independent or assisted and documentation of the walking aid and/or number of assistants required;

- personal activities of daily living (PADL) performance measured on a binary scale as independent or assisted, and specific tasks that require assistance are listed;

- cognition measured on a binary scale as intact or impaired, with measures of either Abbreviated Mental Test score, Mini-Mental State Examination (MMSE), or Cognistat usually documented for those with impaired cognition;

- continence measured on a binary scale as continent or incontinent, and details documented for incontinence;

- premorbid accommodation documents whether patient lives alone, with others, or in assisted accommodation, and the level of care provided at assisted accommodation is detailed.

For the purposes of this study, data recorded on the forms about the patient's age, premorbid and current function (cognition, mobility, PADLs, and continence), and residential status were extracted. Based on the patient's diagnosis, for the purposes of this study, the patient was classified into one of the rehabilitation streams: neurological, musculoskeletal, restorative (deconditioning), spinal, amputee and cardiac. For cognition, the patient was classified as either intact or impaired; for personal care, either independent or assisted; and for continence, continent or incontinent. Mobility was divided into five subcategories: independent with no aid, independent with gait aid, supervision, assisted and nonambulant. Residential status was classified as living alone, with others, or in low-level residential care (LLRC) or high-level residential care (HLRC) facility.

\section{Sample size}

Sample size calculation for logistic regression is a complex problem with most suggestions provided in the literature being based on heuristic subject-to-predictor ratios. ${ }^{16,17}$ 
Long and Freese ${ }^{17,18}$ suggest that sample sizes of less than 100 should be avoided, while several authors on multivariate statistics ${ }^{19-23}$ recommend a minimum ratio of 10 to 1 , with a minimum sample size of 100 or 50 , plus a variable number that is a function of the number of predictors. Following these suggestions, in order to examine up to ten factors associated with the binary outcome, the sample size for this audit was estimated as 200 patients. This estimation was further validated with Precision power method ${ }^{16}$ (expected sample coefficient of multiple determination, 0.5 ; shrinkage factor, 0.2).

\section{Data extraction}

Data on the patients (other than uncomplicated musculoskeletal ones) referred for inpatient rehabilitation was extracted by review of every rehabilitation assessment form for consecutive assessments carried out over a 4-month period. Data related to nurse assessment of uncomplicated musculoskeletal referrals were not included in the analysis due to the absence of standardized assessment forms for these cases, where the decision-making process regarding the need for inpatient rehabilitation is generally less complex and therefore is beyond the scope of this research. A total of 219 consecutive rehabilitation assessment forms were retrieved, covering a 4-month period from July 1, 2009 to October 31, 2009. Of these, 193 had complete data available, and 26 had incomplete documentation. Based on the available baseline information, no evidence of systematic bias or violation of missingness-at-random assumption was detected. All 219 cases were included in the patient demographics and univariate analyses, whilst the 26 incomplete cases were not included in the multivariate analyses.

\section{Statistical analysis}

Statistical analysis was carried out using commercial statistical software, Stata IC (v 11; Stata Corp, College Station, TX, USA). Data were summarized using either mean (standard deviation) or proportions as appropriate. Comparison of premorbid and "at the time of assessment" levels of patients' mobility, cognition, continence, and PADLs was made using McNemar's exact test and corresponding effect sizes for cognition, continence, and PADLs were estimated using the difference in proportions of patients with the specific factor in question. Univariate analyses to examine the relationship between the outcome of admission to inpatient rehabilitation and each of the individual variables were conducted using unpaired $t$-test for age, Fisher's exact tests for purely categorical variables, and tests for trend for variables measured on ordinal scales. Corresponding effect sizes were estimated as either the difference between means or odds ratios.

To investigate the association between multiple independent factors and the outcome, a multiple binary logistic regression model, with inpatient rehabilitation admission or nonadmission as dependent variable and age, rehabilitation stream, residential status, as well as premorbid and current cognition, mobility, function and continence, as independent variables, was used. First, stepwise backward logistic regression model with significance level for removal from the model 0.2 and significance level for addition to the model 0.1 was used. Then the resulting model was subsequently rerun on a complete data set and necessary analyses of fit and collinearity (using Hosmer-Lemeshow statistics and variance inflation factor, respectively) were performed in a standard manner. Likelihood-ratio test was used to confirm that mobility could be used in interval, rather than ordinal form without loss of information. ${ }^{17}$

Approval was obtained from the Ethics Committee of the hospital for analysis and publication of the data. The study also complied with the WMA Declaration of Helsinki.

\section{Results}

\section{Patient characteristics}

The mean age of patients was 65.7 (95\% confidence interval [CI]: 63.7-67.8). In terms of living arrangements, $62.4 \%$ lived with others, $35.1 \%$ lived alone, $1.5 \%$ were in LLRC, and $1.0 \%$ were in HLRC. $38.3 \%$ of patients were classified under the neurological stream, $26.5 \%$ restorative, $20.6 \%$ musculoskeletal, $5.9 \%$ cardiac, $4.6 \%$ spinal, and $4.1 \%$ amputee. Overall, 74.9\% (95\% CI: $68.6-80.5)$ of the 219 patients were accepted for inpatient rehabilitation.

\section{Premorbid versus "at the time of assessment" patient characteristics}

Tables 1 and 2 demonstrate that there is a statistically significant difference between premorbid and current cognition, continence, personal care and mobility, with greater deficits in these areas being experienced at the time of assessment for inpatient rehabilitation compared to the level of function prior to the acute admission.

\section{Univariate analysis}

The univariate analysis (Tables 3 and 4) found a strong association between acceptance for inpatient rehabilitation and the level of cognition, mobility and personal care at the 
Table I Premorbid to current comparison of cognition, continence, and PADLs

\begin{tabular}{|c|c|c|c|c|}
\hline \multirow[t]{2}{*}{ Factor } & \multicolumn{2}{|c|}{ Number (\%) with factor } & \multirow{2}{*}{$\begin{array}{l}\text { Effect size: difference } \\
\text { in proportions with factor } \\
(95 \% \mathrm{Cl})\end{array}$} & \multirow{2}{*}{$\begin{array}{l}\text { P-value } \\
\text { (McNemar's test) }\end{array}$} \\
\hline & Premorbid & At assessment & & \\
\hline Impaired cognition & $18(9.05)$ & $48(24.12)$ & $0.15(0.10,0.21)$ & $<0.001$ \\
\hline Incontinence & $12(6.19)$ & $5 I(26.29)$ & $0.21(0.14,0.26)$ & $<0.001$ \\
\hline Assisted PADLs & $3 \mid(\mid 5.66)$ & $175(88.38)$ & $0.73(0.66,0.79)$ & $<0.001$ \\
\hline
\end{tabular}

Abbreviations: $\mathrm{Cl}$, confidence interval; PADLs, personal activities of daily living.

time of rehabilitation assessment. Patients who were cognitively impaired at assessment were less likely to be accepted (odds ratio $[\mathrm{OR}]=0.31 ; 95 \% \mathrm{CI}: 0.14-0.66 ; P=0.02$ ), whereas patients who required assistance with their mobility $(P<0.001)$ or personal care at assessment $(\mathrm{OR}=20.19 ; 95 \%$ CI: 6.74-66.61; $P<0.001)$ were more likely to be accepted for inpatient rehabilitation. Residential status $(P=0.015)$ and rehabilitation stream $(P=0.004)$ were also found to be associated with the likelihood of admission. Age, as well as premorbid cognition, personal care, continence, and mobility were not significantly associated with the outcome.

Out of 30 patients whose premorbid cognition was intact and who were cognitively impaired at assessment, 26 patients $(87 \%)$ were classified under neurological stream, with the remaining $13 \%$ equally distributed between other streams. Only eight patients (31\%) of neurological stream patients whose premorbid cognition was intact and who were cognitively impaired at assessment were not accepted for rehabilitation.

\section{Multivariable analysis}

The multivariable analysis (Table 5) shows a number of factors that are statistically significantly associated with the outcome of acceptance for inpatient rehabilitation based on the results of multiple logistic regression. The regression model showed acceptable levels of multicollinearity and fit as measured by variance inflation factor (1.33) and Hosmer-Lemeshow statistics $(P=0.38)$ respectively. In terms of premorbid factors, the level of independence with PADLs (adjusted OR $=0.14 ; 95 \%$ CI: $0.03-0.57 ; P=0.006$ )

Table 2 Premorbid to current comparison of mobility status

\begin{tabular}{|c|c|c|c|}
\hline \multirow[t]{2}{*}{ Mobility status } & \multicolumn{2}{|c|}{ Number (\%) with factor } & \multirow{2}{*}{$\begin{array}{l}\text { P-value } \\
\text { (McNemar's } \\
\text { test) }\end{array}$} \\
\hline & Premorbid & $\begin{array}{l}\text { At } \\
\text { assessment }\end{array}$ & \\
\hline Independent, no gait aid & $132(66.67)$ & $16(8.08)$ & 0.002 \\
\hline Independent, gait aid & 57 (28.79) & $19(9.60)$ & \\
\hline Supervised & $3(1.52)$ & $47(23.74)$ & \\
\hline Assisted & $5(2.53)$ & 85 (42.93) & \\
\hline Nonambulant & $\mathrm{I}(0.5 \mathrm{I})$ & $31(15.66)$ & \\
\hline
\end{tabular}

and continence (adjusted $\mathrm{OR}=12.99 ; 95 \% \mathrm{CI}: 1.13-149.72$ $P=0.04)$ were found to influence the likelihood of admission adjusting for the other factors. However, the unusually wide confidence interval for premorbid incontinence would suggest that this could be an aberrant finding. The "at the time of assessment" factors that are significantly associated with the likelihood of admission, adjusting for the other factors, include assistance with PADLs (adjusted $\mathrm{OR}=63.05 ; 95 \%$ CI: 11.1-357.9; $P<0.001$ ), assistance with mobility (adjusted $\mathrm{OR}=2.49$ per category decrease in independence; 95\% CI: 1.33-4.67; $P=0.004)$, incontinence (adjusted OR $=0.15 ; 95 \%$ CI: $0.04-0.64 ; P=0.01$ ) and impaired cognition (adjusted OR $=0.07 ; 95 \% \mathrm{CI}$ : $0.02-0.27$; $P<0.001)$. Living arrangement, rehabilitation stream, and age were not statistically significantly associated with the likelihood of admission, adjusting for the other factors.

\section{Discussion}

To date, there has been a lack of evidence in the literature on formal criteria or guidelines for the most appropriate or efficient methods of patient selection for rehabilitation. ${ }^{24}$

This study empirically confirmed our hypotheses: firstly, we found that there is a difference between premorbid and "at the time of assessment" cognition, continence, personal care, and mobility status of patients being assessed for inpatient rehabilitation, with greater deficits being experienced at the time of assessment for inpatient rehabilitation compared with the level of function prior to the acute admission; and secondly, a number of factors within the routine rehabilitation assessment were found to be significantly associated with the likelihood of patient acceptance for inpatient rehabilitation. Premorbid dependence with PADLs and current impaired cognition as well as incontinence reduce the likelihood of patient selection. On the other hand, current dependence with PADLs and mobility increase the likelihood of patient admission.

The original contribution of this research is that it empirically defines key factors within the available information documented in a routine rehabilitation assessment 
Table 3 Univariate analysis: cognition, continence, PADLs, and age

\begin{tabular}{|c|c|c|c|c|}
\hline \multirow[t]{2}{*}{ Factor } & \multicolumn{2}{|l|}{ Number (\%) } & \multirow{2}{*}{$\begin{array}{l}\text { Odds ratio } \\
\text { (exact } 95 \% \mathrm{Cl} \text { ) }\end{array}$} & \multirow{2}{*}{$\begin{array}{l}\text { P-value } \\
\text { (Fisher's } \\
\text { exact) }\end{array}$} \\
\hline & $\begin{array}{l}\text { Accepted for inpatient } \\
\text { rehabilitation }\end{array}$ & $\begin{array}{l}\text { Not accepted for } \\
\text { inpatient rehabilitation }\end{array}$ & & \\
\hline \multicolumn{5}{|c|}{ Cognition (premorbid) } \\
\hline Impaired & II (6I.II) & $7(38.89)$ & $0.39(0.13-1.3)$ & 0.08 \\
\hline Intact & 147 (79.89) & $37(20.11)$ & & \\
\hline \multicolumn{5}{|c|}{ Incontinence (premorbid) } \\
\hline Incontinent & $10(83.33)$ & $2(16.67)$ & I.2। (0.24-II.88) & $>0.999$ \\
\hline Continent & $148(80.43)$ & $36(19.57)$ & & \\
\hline \multicolumn{5}{|c|}{ PADLs (premorbid) } \\
\hline Assisted & $22(70.97)$ & $9(29.03)$ & $0.64(0.26-1.72)$ & 0.35 \\
\hline Independent & I $38(79.31)$ & $36(20.69)$ & & \\
\hline \multicolumn{5}{|c|}{ Cognition (at assessment) } \\
\hline Impaired & $31(60.78)$ & $20(39.22)$ & $0.31(0.14-0.66)$ & 0.002 \\
\hline Intact & $127(83.55)$ & $25(16.45)$ & & \\
\hline \multicolumn{5}{|c|}{ Incontinence (at assessment) } \\
\hline Incontinent & 42 (77.78) & $12(22.22)$ & $0.78(0.34-1.85)$ & 0.55 \\
\hline Continent & $117(81.82)$ & $26(18.18)$ & & \\
\hline \multicolumn{5}{|c|}{ PADLs (at assessment) } \\
\hline Assisted & I53 (86.44) & $24(13.56)$ & $20.19(6.74-66.61)$ & $<0.00 \mathrm{I}$ \\
\hline \multirow[t]{2}{*}{ Independent } & $6(24.00)$ & $19(76.00)$ & & \\
\hline & Mean (SD) & & Difference $(95 \% \mathrm{Cl})$ & $P$-value (t-test) \\
\hline Age & $65.9(16.08)$ & $65.3(12.43)$ & $-0.61(-4.78-3.56)$ & 0.77 \\
\hline
\end{tabular}

Abbreviations: $\mathrm{Cl}$, confidence interval; PADLs, personal activities of daily living; SD, standard deviation.

that are associated with the decision to select a patient for rehabilitation. Based on the multivariable analysis that was conducted, a number of premorbid and current factors were found to be significantly associated with the outcome of patient acceptance for rehabilitation.

In terms of premorbid function, the only statistically significant factor associated with the likelihood of admission for rehabilitation was the patient's level of independence with self-care. The odds of being accepted for inpatient rehabilitation for patients who required assistance with PADLs prior to hospitalization as compared to the independent patients are reduced by $86 \%$. This could potentially be due to the fact that patients who have pre-existing disabilities tend to have home modifications, supports, and services already in place, and have limited capacity to improve beyond their premorbid level of function.

In regards to current function (ie, level of function at the time of the rehabilitation assessment), cognition, continence, PADLs, and mobility all emerged as statistically significant factors that influence the decision to admit a patient for rehabilitation. Compared to the patients with intact cognition, the odds of being selected for inpatient rehabilitation for patients with impaired cognition are reduced by $93 \%$. This finding reflects the general admission criteria of most rehabilitation units whereby patients should have the capacity to learn new information in order to derive maximum benefit from the therapy provided, and applies particularly in situations where the cognitive impairment is premorbid.

Out of the patients whose cognitive impairment is new rather than premorbid, the majority (87\%) have a neurological diagnosis. These patients have an only slightly lower chance of being accepted for inpatient rehabilitation (69\% vs $75 \%$ ) compared to the overall acceptance rate in our sample. Thus, cognitive rehabilitation, that constitutes an important component of clinical rehabilitation, is provided to patients with such diagnoses as stroke and acquired brain injury when they are deemed likely to benefit from it.

Unfortunately, information was not available from the data collected to determine the degree or nature of cognitive impairment and whether patients who were less impaired were more likely to be admitted compared to those severely affected. Current incontinence was also found to be negatively associated with the likelihood of acceptance to rehabilitation, reducing the odds of acceptance by $85 \%$. This is in keeping with previous studies, which have shown that incontinence is linked with poorer prognosis and outcome in various medical and surgical conditions. ${ }^{25-27}$

The need for assistance with PADLs (adjusted OR $=63.05$; 95\% CI: 11.1-357.9; $P<0.001$ ) and mobility (adjusted $\mathrm{OR}=2.49$ per category decrease in independence; $95 \% \mathrm{CI}$ : $1.33-4.67 ; P=0.004$ ) at the time of assessment were both 
Table 4 Univariate analysis: stream, residential status, mobility

\begin{tabular}{|c|c|c|c|c|}
\hline \multirow[t]{2}{*}{ Factor } & \multirow{2}{*}{$\begin{array}{l}\text { Number with factor } \\
\text { (\% of total number) }\end{array}$} & \multicolumn{2}{|c|}{ Number (\% of total number with factor) } & \multirow{2}{*}{$\begin{array}{l}\text { P-value } \\
\text { (Fisher's exact) }\end{array}$} \\
\hline & & $\begin{array}{l}\text { Accepted for inpatient } \\
\text { rehabilitation }\end{array}$ & $\begin{array}{l}\text { Not accepted for inpatient } \\
\text { rehabilitation }\end{array}$ & \\
\hline \multicolumn{5}{|l|}{ Stream } \\
\hline Total number & $219(100)$ & $164(74.9)$ & $55(25.1)$ & \\
\hline Neurological & $84(38.4)$ & $65(77.4)$ & $19(22.6)$ & 0.004 \\
\hline Musculoskeletal & $45(20.5)$ & $40(88.9)$ & $5(I 1.1)$ & \\
\hline Restorative & $58(26.5)$ & $33(56.9)$ & $25(43.1)$ & \\
\hline Spinal & $10(4.6)$ & $9(90)$ & $\mathrm{I}(\mathrm{I0})$ & \\
\hline Amputee & $9(4.1)$ & $8(88.9)$ & $I(I I . I)$ & \\
\hline Cardiac & $13(5.9)$ & $9(69.2)$ & $4(30.8)$ & \\
\hline \multicolumn{5}{|l|}{ Residential status } \\
\hline Total number & $205(100)$ & $159(77.6)$ & $46(22.4)$ & \\
\hline Living with others & $128(62.4)$ & $104(81.3)$ & $24(18.7)$ & 0.015 \\
\hline Living alone & $72(35.1)$ & $54(75)$ & $18(25)$ & \\
\hline Low-level care & $3(1.5)$ & I (33.3) & $2(66.6)$ & \\
\hline High-level care & $2(1)$ & $0(0)$ & $2(100)$ & \\
\hline \multicolumn{5}{|l|}{ Mobility (premorbid) } \\
\hline Total number & $201(100)$ & $159(79.1)$ & $42(20.9)$ & \\
\hline Independent, no aid & $135(67.2)$ & $105(77.8)$ & $30(22.2)$ & 0.45 \\
\hline Independent, gait aid & $57(28.3)$ & $48(84.2)$ & $9(15.8)$ & \\
\hline Supervised & $3(1.5)$ & $2(66.6)$ & I (33.3) & \\
\hline Assisted & $5(2.5)$ & $3(60)$ & $2(40)$ & \\
\hline Nonambulant & I $(0.5)$ & I $(100)$ & $0(0)$ & \\
\hline \multicolumn{5}{|l|}{ Mobility (at assessment) } \\
\hline Total number & $206(100)$ & $161(78.1)$ & $45(21.8)$ & \\
\hline Independent, no aid & $18(8.7)$ & $5(27.8)$ & $13(72.2)$ & $<0.001$ \\
\hline Independent, gait aid & $21(10.2)$ & $9(42.9)$ & $12(57.1)$ & \\
\hline Supervised & $48(23.3)$ & $43(90)$ & $5(10)$ & \\
\hline Assisted & $86(41.8)$ & $77(90)$ & $9(10)$ & \\
\hline Nonambulant & $33(16)$ & $27(82)$ & $6(18)$ & \\
\hline
\end{tabular}

found to increase the likelihood of selection for inpatient rehabilitation. This would be consistent with the fundamental role of rehabilitation services to restore or maximize the quality of life of patients with functional disability through the provision of intensive physical and occupational therapy programs.

Although only very few patients from low- or high-level care (three patients [1.5\%] and two patients [1\%], respectively) were referred for inpatient rehabilitation, the proportions of patients actually admitted for inpatient rehabilitation differ between these two categories and the other categories of patients. More patients in these two categories were not admitted for inpatient rehabilitation (proportion admitted, $0 \%-33 \%$ ), while this relationship is the opposite for patients living with others or alone (proportion admitted, 75\%-81\%). This qualitative difference is the most likely reason for the statistically significant finding.

In our sample, $25 \%$ of patients that were referred to inpatient rehabilitation were not accepted. These patients were deemed by the assessors to be more appropriate for another discharge destination, namely home (often with a referral for outpatient rehabilitation), GEM unit, palliative care, or residential care, and the referrals are redirected accordingly. It is the important role of the inpatient rehabilitation assessor to exercise judgment on the appropriateness of individual referrals.

The process of assessment and selection of patients is an essential component in the practice of clinical rehabilitation for a number of reasons. Firstly, the supply of rehabilitative care at present is unable to meet the demand. Therefore, rehabilitation service providers are faced with resource allocation issues. Secondly, the effectiveness of a rehabilitation service depends on its ability to identify the patients who are most likely to benefit from the program that it provides. In the setting of constrained resources, a unit that admits every patient referred, regardless of their ability to participate and benefit from the therapy, would not be utilizing its resources appropriately or effectively.

A study by Evans et a $1^{15}$ found that only $21 \%$ of patients who were screened as being eligible for rehabilitation actually ended up receiving it. Two recent studies in stroke 
Table 5 Multivariable analysis of factors associated with the decision to admit for inpatient rehabilitation

\begin{tabular}{|c|c|c|c|}
\hline Factor & $\begin{array}{l}\text { Adjusted odds ratio } \\
\text { for admission* }\end{array}$ & $95 \% \mathrm{Cl}$ & $\boldsymbol{P}$-value** \\
\hline Age (per year of increase) & 0.96 & $0.92-1.01$ & 0.098 \\
\hline Musculoskeletal stream (compared to neurological) & 5.65 & $0.75-42.55$ & 0.093 \\
\hline Restorative (compared to neuro) & 0.39 & $0.12-1.29$ & 0.123 \\
\hline Living alone (compared to living with others) & 0.43 & $0.13-1.44$ & 0.17 \\
\hline Incontinence premorbid (compared to continence) & 12.99 & $1.13-149.72$ & 0.04 \\
\hline Assistance with PADLs premorbid (compared to no assistance) & 0.14 & $0.03-0.57$ & 0.006 \\
\hline Impaired cognition at assessment (compared to intact cognition) & 0.07 & $0.02-0.27$ & $<0.001$ \\
\hline Incontinence at assessment (compared to continence) & 0.15 & $0.04-0.64$ & 0.011 \\
\hline Assistance with PADLs at assessment (compared to no assistance) & 63.05 & II.1 I-357.9 & $<0.001$ \\
\hline Mobility at assessment (per single category in decreasing order & 2.49 & $1.33-4.67$ & 0.004 \\
\hline
\end{tabular}

of independence)

Notes: *The values of odds ratio for admission (compared to non-admission) above (below) I mean an increase (decrease) in odds for admission per a unit of change in an independent variable (or as compared to the reference category); **obtained using stepwise backward logistic regression model with significance level for removal from the model 0.2 and significance level for addition to the model 0.1 ; Nagelkerke's pseudo- $R^{2}=0.47$.

Abbreviation: PADLs, personal activities of daily living.

rehabilitation by Hakkennes et a ${ }^{28,29}$ estimate that $64 \%$ to $81 \%$ of patients who suffered a severe stroke and were referred for inpatient rehabilitation, were accepted for it. These numbers are broadly consistent with the level of acceptance observed in our study. The factors identified by Hakkennes et al that were associated with being accepted for inpatient rehabilitation following severe stroke were younger age, independent premorbid functional status, and higher level of current mobility. While our study also identified premorbid functional status as a factor significantly associated with acceptance to inpatient rehabilitation, the age in our study was not significantly associated with the outcome. With regard to current mobility, our study found that patients who needed assistance with mobility were more likely to be accepted for rehabilitation. This difference from the results by Hakkennes et al can be explained by the differences in the patient populations of interest. While higher levels of mobility in severe stroke patients investigated by Hakkennes et al may be indicative of potential to benefit from intensive rehabilitation, in a more heterogeneous and less severely impaired general population considered in our study, a current need for assistance with mobility indicates an opportunity for improvement in function.

\section{Study limitations}

The data extracted was limited to information documented on the rehabilitation assessment forms. Having more detailed information on various variables, such as cognition, could enhance the interpretation of the results. Specifically, relationship between presence of neglect of aphasia and acceptance for rehabilitation would be of interest for neurological patients. Further prospective studies involving standardized measures of PADLs, mobility and cognition, such as the Adult Functional Independence Measure, MMSE, or Montreal Cognitive Assessment tool would be beneficial. The objective of our study was to investigate multiple rehabilitation streams, which denied us sufficient granularity as far as individual rehabilitation streams are concerned, but allowed us to compare different streams with each other. The design of the current study did not include the comparison of outcomes between accepted and not accepted patients. A further study utilizing linked data that addresses this issue would be of benefit. In addition, the study was conducted in a single center and therefore, generalizability of the findings to other rehabilitation units is uncertain. A future study involving multiple centers would be appropriate.

\section{Conclusion}

The aim of this paper was to reflect existing clinical practice and to investigate whether information routinely collected, as a matter of everyday clinical practice, would prove useful for clinical decision-making. Everyday clinical practice includes significant variability across patient streams, and often precludes using refined assessment tools. Our findings provide researchers, clinicians, and health managers with empirical evidence regarding the process of patient selection for inpatient rehabilitation. This evidence has potential implications for both individual patient's rehabilitation care and inpatient rehabilitation programs resource utilization.

\section{Disclosure}

The authors report no conflicts of interest in this work.

\section{References}

1. Haas JF. Admission to rehabilitation centres: selection of patients. Arch Phys Med Rehabil. 1988;69:329-332. 
2. International Classification of Functioning, Disability and Health (ICF) [webpage on the Internet]. Geneva: World Health Organization; 2012. Available from: http://www.who.int/classifications/icf/en/. Accessed January 10, 2012.

3. Caplan A, Callahan D, Haas J. Ethical and policy issues in rehabilitation medicine. Hastings Cent Rep. 1987;17:1-20.

4. Hersh D. I can't sleep at night with discharging this lady: the personal impact of ending therapy on speech-language pathologists. Int J Speech Lang Pathol. 2010;12(4):283-291.

5. Montgomery K. How Doctors Think: Clinical Judgement and the Practice of Medicine. New York: Oxford University Press; 2005.

6. New PW. The assessment and selection of potential rehabilitation patients in acute hospitals: a literature review and commentary. Open Rehabil J. 2009;2:24-34.

7. Poulos JP, Eagar K. Determining appropriateness for rehabilitation or other subacute care: is there a role for utilisation review? Aust New Zealand Health Policy. 2007;4:3.

8. Wade DT. Selection criteria for rehabilitation services. Clin Rehabil. 2003;17:115-118.

9. Cunningham C, Horgan F, O’Neill D. Clinical assessment of rehabilitation potential of the older patient: a pilot study. Clin Rehabil. 2000;14:205-207.

10. Cooper G, editor. Essential Physical Medicine and Rehabilitation. New York: Humana Press Inc; 2006.

11. O’Young BJ, Young MA, Stiens SA. Physical Medicine and Rehabilitation Secrets, 2nd ed. Philadelphia: Hanley and Belfus Inc; 2001.

12. Association of Academic Physiatrists [homepage on the Internet]. Hanover, MD: Association of Academic Physiatrists (AAP); 1999 through 2012. Available from: http://www.physiatry.org. Accessed November 12, 2012.

13. British Society of Rehabilitation Medicine [homepage on the Internet]. London: BSRM; 2012. Available from: http://www.bsrm.co.uk. Accessed November 12, 2012.

14. Australasian Rehabilitation Outcomes Centre. Report July 2009-June 2010. Wollongong, NSW: Australasian Rehabilitation Outcomes Centre, University of Wollongong; 2010.

15. Evans RL, Haselkorn JK, Bisop DS, Hendricks RD. Characteristics of patients receiving medical rehabilitation. Arch Phys Med Rehabil. 1991;72:685-689.
16. Brooks GP, Barcikowski RS. Precision power method for selecting regression analysis sample sizes. Proceedings of the Mid-Western Educational Research Association Annual Meeting; Oct 1995; Chicago, IL, USA.

17. Long JS, Freese J. Regression Models for Categorical Dependent Variables, 2nd ed. College Station, TX: StataCorp; 2006.

18. Long JS. Regression Models for Categorical and Limited Dependent Variables. Thousand Oaks, CA: Sage Publications; 1997.

19. Peduzzi P, Concato J, Kemper E, Holford TR, Feinstein AR. A simulation study of the number of events per variable in logistic regression analysis. J Clin Epidemiol. 1996;49:1373-1379.

20. Lawley DN, Maxwell AE. Factor Analysis as a Statistical Method. London, UK: Butterworth and Co; 1971.

21. Marascuilo LA, Levin JR. Multivariate Statistics in the Social Sciences: A Researcher's Guide. Monterey, CA: Brooks/Cole; 1983.

22. Tabachnick BG, Fidell LS. Using Multivariate Statistics, 3rd ed. New York, CA: Harper Collins; 1996.

23. Tabachnick BG, Fidell LS. Using Multivariate Statistics, 4th ed Needham Heights, MA: Allyn and Bacon; 2001.

24. Wade DT. Evidence relating to assessment in rehabilitation. Clin Rehabil. 1998;12:183-186.

25. Baztan JJ, Arias E, Gonzalez N, Rodríguez de Prada MI. New-onset urinary incontinence and rehabilitation outcomes in frail older patients. Age Ageing. 2005;34:172-175.

26. Gross JC. Urinary incontinence and stroke outcomes. Arch Phys Med Rehabil. 2000;81:22-27.

27. Johnson MF, Kramer AM, Lin M, Kowalsky JC, Steiner JF. Outcomes of older persons receiving rehabilitation for medical and surgical conditions compared with hip fracture and stroke. J Am Geriatr Soc. 2000;48:1389-1397.

28. Hakkennes S, Hill KD, Brock K, Bernhardt J, Churilov L. Access to rehabilitation following severe stroke: what factors influence the assessor's decision making? J Rehabil Med. Epub 2012.

29. Hakkennes S, Hill KD, Brock K, Bernhardt J, Churilov L. Accessing inpatient rehabilitation following severe stroke: age, mobility, pre-stroke function and hospital unit are associated with discharge to rehabilitation. Int J Rehabil Res. Epub 2012.
Clinical Audit

\section{Publish your work in this journal}

Clinical Audit is an international, peer-reviewed, open access journal focusing on the processes and outcomes of clinical audit in any area of healthcare. All aspects of patient care are addressed within the journal and practitioners from all disciplines are invited to submit their work. Areas covered include: Publication of audits; How an audit has changed practice;

\section{Dovepress}

Practical tips on how to do audits and to avoid pitfalls; How audits have changed patient care; Calls and justifications for new audits. The manuscript management system is completely online and includes a very quick and fair peer-review system, which is all easy to use. Visit http://www.dovepress. com/testimonials.php to read real quotes from published authors. 